\title{
Percepção de estudantes de graduação sobre a importância da disciplina Odontologia para Pacientes com Necessidades Especiais
}

\author{
Tamires Daiane da Silva*; Natalia Garcia Santaella*; Raquel D'Aquino Garcia Caminha*; Paulo \\ Sérgio da Silva Santos**
}

* Mestranda, Departamento de Cirurgia, Estomatologia, Patologia e Radiologia, Faculdade de Odontologia de Bauru, USP

** Professor Doutor, Departamento de Cirurgia, Estomatologia, Imaginologia e Radiologia, Faculdade de Odontologia de Bauru, USP

Recebido em 23/07/2019. Aprovado em 28/11/2019.

\begin{abstract}
RESUMO
Pessoas com necessidades especiais (PNE) representam 10\% da população mundial e suas particularidades, somadas à falta de conhecimentos teóricos e experiência clínica, fazem com que os cirurgiões-dentistas se sintam inaptos para atendê-los. Sendo assim, o objetivo desse estudo foi identificar a importância percebida pelos estudantes de Odontologia sobre a disciplina Odontologia para Pacientes com Necessidades Especiais (OPNE). Trata-se de um estudo exploratório, descritivo e qualitativo, que realizou a coleta de dados por meio de questionários aplicados a 29 estudantes ao final da disciplina optativa de OPNE da Faculdade de Odontologia de Bauru (FOB). Os estudantes reconhecem que a ausência de contato com PNE durante o curso acarretará insegurança profissional para realizar o atendimento odontológico desses pacientes, dificultando assim o acesso a saúde bucal desta população. A disciplina de OPNE, neste estudo, possibilitou ao estudante de aprender, conviver e realizar atendimento odontológico adequado e humanizado ao PNE.
\end{abstract}

Descritores: Pessoas com Deficiência. Assistência Odontológica para Doentes Crônicos. Odontologia. Educação em Odontologia. Estudantes de Odontologia.

\section{INTRODUÇÃO}

As pessoas com necessidades especiais (PNE) representam $10 \%$ da população mundial ${ }^{1}$, podendo apresentar como características alterações físicas, motoras, mentais e sociais de forma simples ou complexa, temporária ou permanente, regressiva, estável ou progressiva, necessitando de atendimento por equipe especializada ${ }^{2,3}$. As limitações físicas e intelectuais das PNE, como por exemplo dificuldades motoras, sialorréia, 
macroglossia, apinhamento dental, hiper ou hipomotricidade, deficiência mental, além da discriminação ou superproteção familiar, resultam em negligência com a saúde bucal $^{4-5}$. As particularidades desses pacientes, somada à falta de conhecimentos teóricos e experiência clínica faz com que os cirurgiões-dentistas se sintam inaptos para o atendimento desses pacientes ${ }^{5-7}$.

A mudança desse cenário poderá ocorrer por meio da participação dos estudantes em atendimentos especializados para PNE dentro das instituições de ensino, além de inserir a Odontologia para Pacientes com Necessidades Especiais (OPNE) como disciplina obrigatória nos currículos dos cursos de Odontologia ${ }^{7-9}$. O Conselho Federal de Odontologia regulamentou, no ano de 2002, a especialidade "Odontologia para Pacientes com Necessidades Especiais", entretanto, o atendimento odontológico para estes pacientes ainda é considerado um desafio pela escassez de profissionais habilitados ${ }^{9,10}$.

$\mathrm{Na}$ Faculdade de Odontologia de Bauru (FOB), Universidade de São Paulo, a disciplina optativa de OPNE é oferecida no sétimo período do curso, com duração de aproximadamente dois meses, carga horária total de 30 horas (16 horas de aulas teóricas e 14 horas de prática clínica), com vagas limitadas (16), disponibilizadas aos estudantes interessados que apresentarem as melhores médias ponderadas no histórico escolar. O objetivo da disciplina é capacitar o estudante a identificar as doenças sistêmicas de PNE e determinar o diagnóstico e abordagem terapêutica odontológica para cada caso em particular, a fim de prover atendimento odontológico seguro e eficaz ${ }^{11}$. Desta forma, este estudo tem como objetivo identificar a importância percebida pelos estudantes de Odontologia sobre a disciplina OPNE.

\section{METODOLOGIA}

Trata-se de um estudo exploratório, descritivo e qualitativo, que realizou a coleta de dados por meio de questionário (figura 1) aplicado aos estudantes ao final da disciplina de OPNE da FOB. O instrumento era composto de oito questões, sendo cinco de múltipla escolha, duas dissertativas e uma autoavaliativa, com o objetivo de obter a avaliação do estudante quanto a disciplina cursada.

Os dados das questões objetivas foram tabulados e as respostas das questões dissertativas foram agrupadas de acordo com a significação e compreensão dos questionamentos realizados. A identidade dos estudantes foi preservada e o projeto foi aprovado pelo Comitê de ética Institucional sob o parecer 30228420.2.0000.5417.

Os temas ministrados na disciplina foram Odontologia em Oncologia, Transplantes de Órgãos e Tecidos, Coagulopatias, Cardiopatias, Endocrinopatias, Distúrbios Neuropsicomotores, Multidisciplinaridade em Oncologia e Interface com a Fonoaudiologia. O componente prático consistiu no atendimento do PNE em atividades clínicas, além de uma visita hospitalar para conhecer as atividades da área de Odontologia Hospitalar.

\section{RESULTADOS}

Foram avaliadas duas turmas, sendo a primeira composta por 13 estudantes e a segunda por 16, totalizando 29 questionários preenchidos pelos estudantes de graduação do curso de Odontologia da FOB que optaram por cursar a disciplina OPNE. Um estudante da primeira turma não estava presente no dia em que o questionário foi aplicado e por este motivo não participou da avaliação da disciplina.

Todos os estudantes da primeira turma julgaram que o conteúdo proposto pela disciplina foi adequado; já para a segunda turma, 14 estudantes julgaram que o conteúdo era adequado, contudo, dois estudantes julgaram que o conteúdo proposto pela disciplina não foi adequado.

$\mathrm{Na}$ questão referente aos conteúdos 
abordados, todos os estudantes de ambas as turmas, opinaram que houve coerência com os objetivos propostos e reconheceram a importância e relevância dos mesmos.
Quanto a coerência dos assuntos com os objetivos propostos, todos os estudantes (turma $1 \mathrm{e}$ 2) opinaram que houve coerência e reconheceram sua importância e relevância.

QUESTIONÁRIO

\section{Disciplina: Odontologia para Pacientes com Necessidades Especiais}

Em sua opinião, o conteúdo proposto pelo programa foi:
( ) Insuficiente
( ) Ideal
( ) Excessivo

O conteúdo das aulas foi coerente com os objetivos propostos no programa:
( ) $\mathrm{Sim}$
( ) Parcialmente
( ) Não

Em sua opinião, a disciplina tem carga horária:
( ) Insuficiente
( ) Adequada
( ) Excessiva

As atividades realizadas no período foram relevantes para a compreensão desta disciplina:
( ) Sim
( ) Parcialmente ( ) Não

Qual contribuição desta disciplina para sua formação?

Quanto à eficácia didática oferecida pela disciplina, esclarecimento de dúvidas e o formato de seminários, como você pontua de 0 a 10 ?

Sua autoavaliação de 0 a 10 para cada item:

Assiduidade e pontualidade

Dedicação à clínica

Aprendizagem na clínica e seminários

Nota final para a sua participação na disciplina

Comentários e sugestões:

Figura 1. Questionário para avaliação da Disciplina de Pacientes com Necessidades Especiais

A carga horária foi considerada como adequada para $10(76,92 \%)$ dos estudantes da primeira turma, e $3(23,07 \%)$, consideraram insuficiente. $\mathrm{Na}$ segunda turma, $12 \quad(75 \%)$ estudantes consideraram a carga horária adequada e $4(25 \%)$ a consideraram insuficiente.

Todos os participantes (100\%), de ambas as turmas, relataram a importância da disciplina para 
a sua formação e reconheceram que as PNEs necessitam de manejo diferente dos pacientes considerados normorreativos, respostas evidenciadas pelas opiniões a seguir.

"Com certeza teve grande contribuição para que, como profissional, eu seja capaz de oferecer atendimento $e$ orientação adequados a esses pacientes, os quais tornam um grupo cada vez mais representativo na sociedade e que demanda cuidados odontológicos" (primeira turma Al).

"Uma nova visão para o atendimento de pacientes com comprometimento sistêmico ou neurológico, principalmente em relação a parte prática, onde foi possível aplicarmos os conhecimentos da aula teórica foi um grande enriquecimento profissional quanto pessoal" (primeira turma - A3).

"Essa disciplina contribuirá muito para minha formação, uma vez que, além de ensinar os conteúdos teóricos sobre esses temas pouco abordados na graduação, também nos ensinou para a prática clínica e manejo do paciente o que será um diferencial em minha formação" (primeira turma - A9).

"A disciplina foi de extrema importância para minha formação, pois pude aprender muito com a disciplina, pude entender melhor a especialidade, vivenciar a rotina clínica com os pacientes, além de ter sido uma oportunidade muito gratificante pessoalmente" (segunda turma-A5).

"Acredito que a maior contribuição foi perceber que o paciente sistemicamente comprometido não deve ser negligenciado por conta de sua condição e que temos o conhecimento adequado para atendê-los" (segunda turma-A6).

"Tanto no quesito profissional quanto pessoal ela contribui para ampliar os conhecimentos do paciente como um todo e permitir entender que estamos aptos a atender pacientes sistemicamente comprometidos" (segunda turma-A16).

Os estudantes da primeira e segunda turmas avaliaram fatores como eficácia da didática, esclarecimentos de dúvidas e formato dos seminários e a resposta unânime foi 10 para todas essas questões.

A autoavaliação foi dividida em 4 tópicos, com nota de 0 a 10 para cada um deles, sendo que assiduidade e pontualidade receberam nota média de 9,84 pela primeira turma e 9,59 pela segunda turma; dedicação à clínica pela primeira turma, 9,84 e pela segunda turma, média 9,78; aprendizagem na clínica e seminários pela primeira turma, média 9,76, já para a segunda turma, 9,96; e nota final 9,76 pela primeira turma, e nota final 9,54 para a segunda turma.

Para a primeira turma, as sugestões e comentários sobre a disciplina mais citadas foram que a disciplina deveria ter maior quantidade de horas voltadas ao atendimento clínico (3 - 23,07\%) e possibilidade de acompanhamento das atividades de atendimento hospitalar e clínica multidisciplinar junto a equipe da pós-graduação da Estomatologia da FOB (5 - 38,46\%).

Para a segunda turma, as sugestões e comentários sobre a disciplina foram semelhantes; sendo as mais citadas que a disciplina deveria ter maior quantidade de horas voltadas ao atendimento clínico e aula teórica para abordargem de outros temas $(7-43,75 \%)$, e por conseguinte, o impacto positivo que essa disciplina teve para a formação profissional $(6-37,5 \%)$.

\section{DISCUSSÃO}

As respostas da avaliação da disciplina de OPNE evidenciaram sua importância no que diz respeito ao manejo adequado e tratamento humanizado do paciente que apresenta qualquer tipo de necessidade especial. Os estudantes 
avaliados reconhecem que a ausência de contato com PNE durante o curso acarretará insegurança profissional para realizar seu atendimento odontológico, dificultando assim o acesso desta população a uma boa saúde bucal.

Em sua maioria, os estudantes enfatizaram que gostariam de maior carga horária, tanto na prática clínica quanto aulas teóricas, visando a obtenção de maior experiência, confiança e segurança para a sua vida profissional. Assim, acredita-se que uma disciplina direcionada a pacientes especiais deveria ser obrigatória, pois assim contribuiria positivamente para que todos os estudantes tivessem contato e pudessem oferecer atendimento a estes indivíduos.

Por outro lado, sabe-se também que há poucos professores nesta área. Por este motivo, observa-se um efeito circular, em que a quantidade de professores reduzida para ministrar aulas de OPNE resulta em um acesso limitado de alunos à disciplina. No presente estudo, por exemplo, apenas 29 (29\%) de um total de 100 estudantes tiveram contato com estes pacientes e $10(34,48 \%)$ ainda referiram que deveria haver uma carga horária maior, evidenciando que, mesmo tendo contato, não se sentem preparados para atender esses indivíduos em sua prática profissional.

Essa premissa vai na contramão do proposto no artigo $3^{\circ}$ das Diretrizes Curriculares Nacionais $(\mathrm{DCN})^{12}$, onde é frisado que o cirurgião-dentista deve estar "[...]Capacitado ao exercício de atividades referentes à saúde bucal da população, pautado em princípios éticos, legais e na compreensão da realidade social, cultural $e$ econômica do seu meio, dirigindo sua atuação para a transformação da realidade em benefício da sociedade".

Sabe-se que, numa mesma turma de Odontologia, existirão os profissionais que optarão por seguir a carreira clínica e os que optarão pela carreira acadêmica, ou ambas, e por sua vez, não atenderão PNE, nem tampouco ministrarão essa disciplina por insegurança de não ter aprendido o suficiente na graduação ou ainda por não ter tido nenhum contato com este grupo de pacientes ${ }^{13}$.

O conteúdo ministrado na disciplina de OPNE abrange a identificação das diversas doenças sistêmicas de PNE como diabetes, hipertensão, pacientes oncológicos, pacientes transplantados e pacientes com distúrbios neuropsicomotores, diagnósticos de sua saúde bucal e manejo odontológico. O conteúdo abordado foi avaliado de maneira positiva por unanimidade entre os estudantes. A não obrigatoriedade da disciplina não estimula a universidade a contratar professores especializados em PNE, retornando à questão discutida anteriormente em relação à limitação do acesso dos estudantes a esses conteúdos.

A prática clínica também foi relevante para a compreensão da disciplina de acordo com a avaliação realizada. Sabe-se que atividades práticas são essenciais para a assimilação do conteúdo teórico ministrado ${ }^{14} \mathrm{e}$, nesta disciplina, houve o atendimento clínico aos PNE. Os atendimentos, inclusive, despertaram ainda mais o interesse dos estudantes, que sugeriram maior número de horas e acompanhamento do paciente até a finalização do caso, referindo ainda que além de um enriquecimento profissional, existe também o pessoal, o que nos permite dizer que a humanização em saúde também esteve presente nos atendimentos das PNE.

\section{CONCLUSÃO}

A disciplina OPNE, neste estudo, mostrou-se importante, pois possibilitou ao estudante aprender, conviver e realizar atendimento odontológico adequado e humanizado ao PNE, despertando o interesse unânime daqueles que optaram por cursar a disciplina.

\section{AGRADECIMENTO}

O presente estudo foi realizado com apoio da 
Coordenação de Aperfeiçoamento de Pessoal de Nível Superior - Brasil (CAPES) - Código de Financiamento 001.

\section{Abstract \\ Perception of graduation students about the importance of Dentistry's discipline for patients with special needs}

People with special needs (PSN) represent 10\% of the world population and their particularities, added with the lack of theoretical knowledge and clinical experience, make dentists feel unable to attend to them. Therefore, the objective of this study was to identify the importance of dentistry students in the discipline of dentistry for patients with special needs (DPSN). This is an exploratory, descriptive, and qualitative study, for which data were collected through a questionnaire administered to 29 students at the end of the DPSN discipline at the Bauru School of Dentistry (BSD). Students recognized that the lack of contact with PSN during the course may cause professional insecurity in providing dental care to these patients, thus making access to oral healthcare difficult for this population. The DPSN discipline in this study enabled students to learn, live with, and provide adequate and humanized dental care to the PSN population.

Descriptors: Disabled Persons. Dental Care for Chronically Ill. Dentistry, Education. Dental, Students.

\section{REFERÊNCIAS}

1. Brasil. Ministério da Saúde. Secretaria de Atenção à Saúde. Política Nacional de Saúde da Pessoa Portadora de Deficiência. Brasília: Editora do Ministério da Saúde; 2008. [Acesso em 21 de jan. de 2019]. Disponível em: http://bvsms.saude.gov.br/bvs/publicacoes/ politica_nacional_saude_pessoa_deficiencia .pdf.

2. World Health Organization. International Classification of Functioning, Disability and Health. Geneva; 2001. [Acesso em 24 de jan. de 2019]. Disponível em: https:// www.who.int/classifications/icf/en/.

3. Resende VLS. A odontologia e o paciente especial. Jornal de Odontol do CROMG. 1998; 18:12.

4. Sampaio EF, César FN, Martins MGA. Perfil odontológico dos pacientes portadores de necessidades especiais atendidos no instituto de previdência do Estado do Ceará. RBPS. 2004;17(3):127-34.

5. Resende VLS, Castilho LS, Viegas CMS, Soares MA. Fatores de risco para a cárie em dentes decíduos de Portadores de Necessidades Especiais. Pesq Bras Odontoped Clin Integr. 2007; 7(2):111-7.

6. Crespi VP, Ferguson FS. Approaching Dental care for the developmentally disabled: a guide for the dental practicioner. NY State Dent J. 1987; 53(2):29-32.

7. Amaral COF, Aquotte APC, Aquotte LC, Parizi AGS, Oliveira A. Avaliação das expectativas e sentimentos de alunos de Odontologia frente ao atendimento de pacientes com necessidades especiais. RFO UPF. 2011; 16(2):124-9.

8. Martins SMS, Andrade CES, Andrade GTS, Agripino GG, Silva NB, Cardoso AMR. Abordagem da Disciplina de PNE nos Currículos de Odontologia das Instituições de Ensino Superior do Nordeste do Brasil. REVICO. 2018; 16(3):37-45.

9. Penha ES, Tenório DA, Fonseca FRA, Guênes GMT, Montagna E. Caracterização do componente curricular Odontologia para Pacientes com Necessidades Especiais nos cursos de Odontologia do estado da Paraíba. Rev ABENO. 2018; 18(2):13-9.

10. Queiroz F, Rodrigues MMLF, Cordeiro Junior GA, Oliveira JD, Almeida ER. Avaliação das condições de saúde bucal de Portadores de Necessidades Especiais. Rev Odontol UNESP. 2014; 43(6):396-401. 
11. FOB/USP. Projeto Pedagógico - Curso de Odontologia. [Acesso em 21 de jan. 2019]. Disponível em: http://graduacao.fob.usp.br/ cursos/odontologia/.

12. Brasil. Ministério da Educação. Resolução $\mathrm{n}^{\circ} \mathrm{CNE} / \mathrm{CES} 3 / 2002$ de 19 de fevereiro de 2002. Institui as Diretrizes Curriculares Nacionais dos Cursos de Farmácia e Odontologia. Diário Oficial, Brasília, 4 mar 2002, seção 1, p. 10. [Acesso em 11 de fev. de 2019]. Disponível em: http://portal.mec. gov.br/cne/arquivos/pdf/CES032002.pdf.
13. Ferreira SH, Suita RA, Rodrigues $\mathrm{PH}$, Kramer PF. Percepção de estudantes de graduação em Odontologia frente ao atendimento de pessoas com deficiência. Rev ABENO. 2017; 17(1):87-96.

14. Jacomine JC, Ferreira R, Sant'ana ACP, Rezende MLR, Greghi SL, Damante CA, et al. Saúde bucal e pacientes com necessidades especiais: percepção de graduandos em Odontologia da FOB-USP. Rev ABENO. 2018; 18(2):45-54.

\section{Correspondência para:}

Tamires Daiane da Silva e-mail: tamires_psico@usp.br Universidade de São Paulo Al. Dr. Octávio Pinheiro Brisolla, 9-75, 17012-901 Bauru, São Paulo/SP 